\title{
Ultrasonic-assisted hydrothermal synthesis and catalytic behavior of a novel SAPO-34/Clinoptilolite nanocomposite catalyst for high propylene demand in MTO process
}

\author{
Eshagh Moradiyan ${ }^{1}$, Rouein Halladj $^{* 1}$, Sima Askari ${ }^{2}$ and Parisa Moghimpour Bijani ${ }^{3}$ \\ ${ }^{1}$ Faculty of Chemical Engineering, Amirkabir University of Technology, Tehran Polytechnic, \\ P.O. Box 15875-4413, Hafez Ave., Tehran, Iran. Fax: +98 2166405847; Tel: +98 2164543151 \\ ${ }^{2}$ Department of Chemical Engineering, Science and research branch, Islamic azad university, \\ Tehran, Iran. \\ ${ }^{3}$ Catalyst Research Group, Petrochemical Research and Technology Company, National \\ Petrochemical Company, P.O. Box 1435884711, Tehran, Iran \\ Corresponding author: \\ * Rouein Halladj \\ Professor, \\ Faculty of Chemical Engineering \\ Amirkabir University of Technology \\ e-mail: halladj@aut.ac.ir \\ Phone: +98 2164543151 \\ Fax: +98 2166405847
}


Abstract: SAPO-34 as a catalyst has high selectivity and hydrothermal stability, but it is rapidly deactivated by the formation of coke in its micropores. Evaluating the natural Clinoptilolite capability as a binder in nanocomposite catalysts is of interest because of its low cost, and accelerating the reaction. The SAPO-34/Clinoptilolite (S/C) nanocomposite catalysts were synthesized via ultrasonic-assisted hydrothermal method using Clinoptilolite as a binder. Subsequent performance of the catalyst was investigated in the methanol to olefins (MTO) reaction. The structures of synthesized nanocomposite were characterized with several methods such as XRD, XRF, FESEM, TEM, $\mathrm{NH}_{3}$-TPD, FT-IR, and nitrogen adsorption techniques. The modified Clinoptilolite was attained using nitric acid treatment. Although the physicochemical analysis indicated that $\mathrm{HNO}_{3}$-treatment decreases the crystallinity of the Clinoptilolite, the specific surface area of natural zeolite enhances considerably from 20.07 to $187.8 \mathrm{~m}^{2} / \mathrm{g}$. The nanocomposite catalysts showed high selectivity toward light olefins with $100 \%$ conversion and $90 \%$ selectivity to light olefins as desired products at $450^{\circ} \mathrm{C}$. Nanocomposite with the additional diffusion paths for mass transfer provided by binder-filled space ascend to higher catalytic lifetimes in compare with free SAPO-34 catalyst.

Key-words: SAPO-34/Clinoptilolite, nanocomposite catalysts, MTO process, ultrasonic-assisted hydrothermal method 


\section{Introduction}

Besides the rising of the global crude oil price, there is an increasing demand for ethylene and propylene as an essential raw materials for polyolefin production which consequently drawn the attention of researchers to catalytic conversion of methanol to light olefins (MTO) process [1, 2]. Since, Zeolitic molecular sieves based on uniform three dimensional nano-channels have different strength of acid sites and portions, they become indispensable members for separation and catalytic processes [3, 4]. Natural Zeolite nanocomposites catalyst can be used for more investigation due to their structural and functional similarities such as large surface area, valuable ion exchange capability and their eco-friendly nature compared with other vastly used catalysts [5]. Accordingly, unique features such as micropores, and proper acidic strength make SAPO-34 the most common catalyst manipulated in the MTO process [6-8]. Thus, SAPO-34 has high selectivity, and high hydrothermal stability; however, it is rapidly deactivated by the formation of coke in its micropores [9-11].

Until the present time, considerable efforts have been made to ameliorate the selectivity and activity of the SAPO-34 catalysts in light olefins production including changes in initial components, structure directing agent, and synthesis conditions $[12,13]$. In some studies, SAPO34 has been used as a composite with a second component, e.g. $\mathrm{ZrO}_{2}$ [14], graphite [15] and ceramic [16]. Many researches have investigated the effect of particle size, and dispersion of nanocatalysts in different methods and it was found that sonochemical technique provides better performance with more affordable cost [13, 17-20].

Among inorganic materials, Clinoptilolite is a natural zeolite aluminum silicate with a $\mathrm{Si} / \mathrm{Al}$ ratio of 4-6.5 which is widely used in various environmental and industrial applications due to its abundant and low-cost sources [21]. Clinoptilolite zeolites have been previously exposed to 
modification by acid or base treatments. For example, through acid treatment, the framework dealumination leads to soar sorption and form mesopore [20, 22-24]. Using additional component as a substrate or filler for the phase growth has recently received considerable attentions in preparation of the nanocomposite materials [25]. This strategy is based on modifying the surface of nanocatalysts, and applies hierarchy to the pores [26]. The coexistence of individual components with different functionalities and pore structures causes synergistic behavior in most cases. It is worth being mentioned that the most important function of the matrix is to enhance the intraparticle transportation of both reactants and products [27, 28].

The catalysts based on Clinoptilolite have been studied in methanol conversion [29], propane dehydrogenation process [30], direct synthesis of dimethyl ether [5], catalyst for the selective catalytic reduction of $\mathrm{NOx}$ by ammonia $\left(\mathrm{NH}_{3}-\mathrm{SCR}\right)$ [31] and adsorbents [32-35]. Moreover, the nanocomposites based on SAPO-34 have been studied in propane dehydrogenation process (ZSM-5/SAPO-34 and SAPO-34/ZSM-5) [36], dimethyl ether conversion to light olefins $\left(\mathrm{SAPO}-34 / \mathrm{ZrO}_{2}\right)$ [14], ethanol conversion to propylene (HZSM-5/SAPO-34) [37, 38], and methanol conversion to olefins (ZSM-5/SAPO-34) [9].

In this research, a novel a novel nanocomposite catalysts including silicoaluminophosphate (SAPO) and modified Clinoptilolite have been presented. The major aim is to use sonochemical technique in order to disperse nanoparticles in Clinoptilolite as a catalytic binder in synthesis of SAPO-34/Clinoptilolite (S/C) nanocomposite. Combining SAPO-34 with CHA and Clinoptilolite with HEU structure, leads to the prepared hierarchical composite ascertains useful physicochemical properties of the mentioned types of zeolites alongside with the improvement in surface properties and modified distribution of active centers. 
Although there are several reports on the fabrication of SAPO-34 composite catalyst applied to MTO reaction, but there is no report on fabrication of S/C composite and the impact of ultrasonic assisted hydrothermal procedure. Physiochemical properties of the composite catalysts and physical mixture of SAPO-34 and Clinoptilolite were identified by XRD, FESEM, EDX, BET and FTIR techniques. In addition, their catalytic performance in the MTO reaction were evaluated. S/C composite prepared by ultrasonic assisted hydrothermal synthesis showed high selectivity toward light olefins and good catalytic stability due to its special properties.

\section{Materials and methods}

\subsection{Catalyst preparation}

Natural Iranian zeolites from Semnan province was used as a binder. Preparing the Silicoaluminophosphate/Clinoptilolite nanocomposite catalysts through three main steps schematically illustrated in Fig. 1. In the first step (a), in order to obtain $\mathrm{H}^{+}$-zeolite with a high degree of $\mathrm{H}^{+}$-exchange, Clinoptilolite powder acid is treated with $\mathrm{HNO}_{3}$ solution. In the second step (b), precursor SAPO-34 gel with molar ratio of $1 \mathrm{Al}_{2} \mathrm{O}_{3}: 1 \mathrm{P}_{2} \mathrm{O}_{5}: 0.8 \mathrm{SiO}_{2}: 8.0$ DEA: $20 \mathrm{H}_{2} \mathrm{O}$ was prepared. The sources of the framework elements for $\mathrm{P}$ and $\mathrm{Al}$ were $\mathrm{H}_{3} \mathrm{PO}_{4}$ [85 wt\% aqueous solution, Merck], and Aluminum isopropoxide [98\% Al (OPri) 3 , Merck] respectively. Diethylamin [DEA, 99 wt $\%$, Merck] was used as the structure directing agents. For the primary gels, Tetraethyl orthosilicate [TEOS, Merck] was selected as a silica source. Finally, at the third step (c), modified Clinoptilolite was mixed with SAPO-34 gel, stirred for an hour, and then the resulting gel was irradiated with ultrasound at a frequency of $24 \mathrm{kHz}$. The primary gel was placed into a $40 \mathrm{ml}$ Teflon-lined stainless steel autoclave, and heated in an oven at $190{ }^{\circ} \mathrm{C}$ for 24 h. The final solid product was recovered, and washed three times by centrifuging with distilled 
water, and then it dried at $120{ }^{\circ} \mathrm{C}$ for $12 \mathrm{~h}$. Suitable experimental conditions to calcinate the synthesized crystals were found to be $500{ }^{\circ} \mathrm{C}$ in the air for $4 \mathrm{~h}$.

(a) Modification of Clinopetilolite
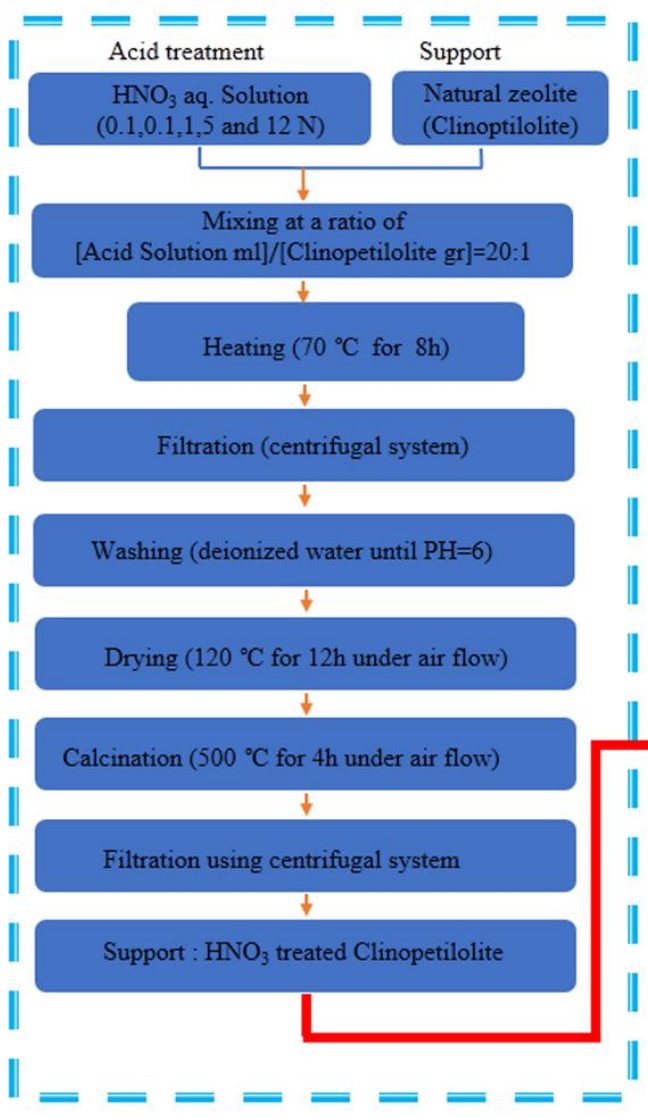

(b) Preparation of SAPO-34 Gel

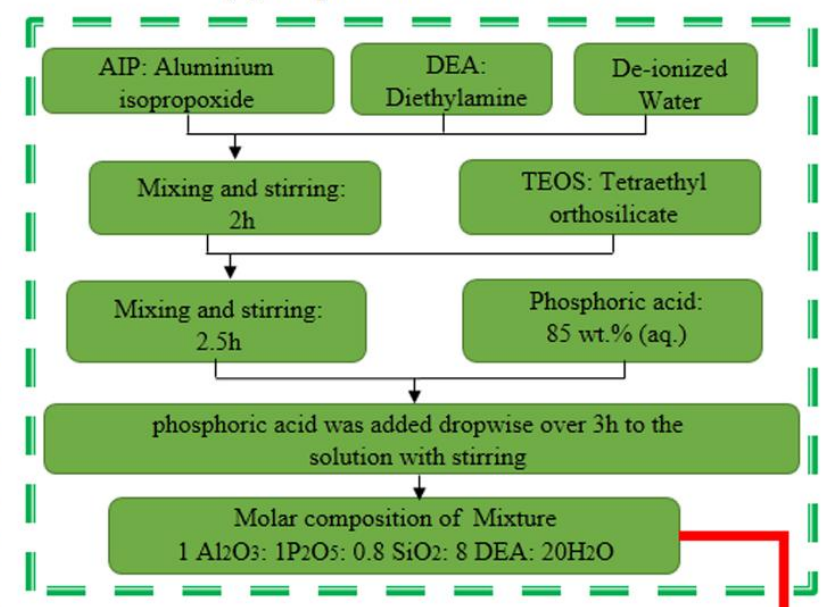

(c) Design of composite catalyst system

$\rightleftharpoons=\overline{=}=\overline{=}=\overline{=}$

\section{Mixing, stirring (1h) and ultrasonication (1h)}

Hydrothermal crystallization $\left(190^{\circ} \mathrm{C}\right.$ for $\left.24 \mathrm{~h}\right)$

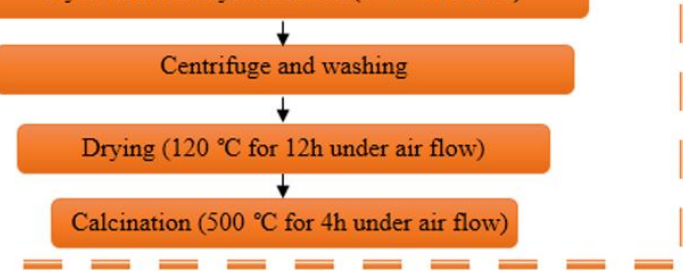

Figure 1. Schematic flow chart for (a) treatment of Clinoptilolite using $\mathrm{HNO}_{3}$, (b) preparation of SAP-34 gel and (c) design of composite catalyst system.

\subsection{Catalyst characterization}

The phase and crystallinity of the samples were analyzed by X-ray diffractometer (Equinox $3000)$ operated at $30 \mathrm{~mA}$ and $40 \mathrm{kV}$ with a $\mathrm{Cu} \mathrm{KaX}$-ray source $\left(\lambda=1.54056{ }^{\circ} \mathrm{A}\right)$ at ambient temperature. The particle morphology was identified using a Zeiss Sigma VP field-emission electron microscope (FESEM). The chemical composition of calcinated samples was determined by X-ray florescence technique (XRF; Philips PW 1480). Transmission electron microscopy 
(TEM) was performed with a Philips CM200 at $200 \mathrm{KV}$ electron microscope. Ammonia temperature programmed desorption $\left(\mathrm{NH}_{3}-\mathrm{TPD}\right)$ carried out in the temperature range of $50-800$ ${ }^{\circ} \mathrm{C}$ using a $0.2 \mathrm{~g}$ of catalyst under $2 \% \mathrm{NH}_{3} / \mathrm{He}$ gas mixture stream $(60 \mathrm{~N} \mathrm{ml} / \mathrm{min})$ from ambient temperature up to $800{ }^{\circ} \mathrm{C}$ at a heating rate of $10{ }^{\circ} \mathrm{C} / \mathrm{min}$. Moreover, catalyst samples in all samples were treated in a He flow rate of $60 \mathrm{~N} \mathrm{ml} / \mathrm{min}$ for $1 \mathrm{~h}$ and during this period the temperature was raised from ambient temperature up to $800{ }^{\circ} \mathrm{C}$ at a heating rate of $10^{\circ} \mathrm{C} / \mathrm{min}$.

Textural properties of calcinated samples counting total surface area, total pore volume, micropore volume, and average pore diameter were calculated via BET (Brunauer, Emmett and Teller), t-plot, and BJH (Barrett-Joyner-Halenda) methods. Isotherm data of nitrogen adsorption in the relative pressure ( $\mathrm{P} / \mathrm{P} 0)$ ranges from 0.05 to 0.30 obtained at $77.35 \mathrm{~K}$ using Quantachrome Autosorb-1 analyzer. FT-IR spectrum was measured using KBr-diluted pellet on an IR spectrophotometer (PerkinElmer).

\section{Results and discussions}

\section{1. $\mathrm{HNO}_{3}$-modified Clinoptilolite}

The treatment of the natural zeolitic with $\mathrm{HNO}_{3}$ led to the dealumination (hydrolysis of Al-OSi bonds) and exchange of the cations by hydronium ions $\left(\mathrm{H}_{3} \mathrm{O}+\right)$. Table 1 shows the elemental composition of the non-treated and treated Clinoptilolite according to the XRF analysis. The $\mathrm{Si} / \mathrm{Al}$ ratio of natural Clinoptilolite is 3.2 (wt. \%), which is a common value for this natural zeolite. Although different Si/Al ratios have been reported for Clinoptilolite, all of them are within the range of 4-6.5 (wt. \%). In this research, the $\mathrm{HNO}_{3}$ treatment increased the Si/Al ratio in Clinoptilolite from 3.2 to 8.8 (wt. \%). 
Table 1. Characterization data of the samples.

\begin{tabular}{cccccccccccc}
\hline \multirow{2}{*}{\begin{tabular}{c} 
Sample name \\
\cline { 2 - 11 }
\end{tabular}} & $\mathrm{Si}$ & $\mathrm{Al}$ & $\mathrm{Fe}$ & $\mathrm{Na}$ & $\mathrm{K}$ & $\mathrm{Ca}$ & $\mathrm{P}$ & $\mathrm{Ti}$ & $\mathrm{Mn}$ & $\mathrm{Mg}$ \\
\hline Natural Clinoptilolite & 62.2 & 19.3 & 1.8 & 6.07 & 6.7 & 3.2 & 0.03 & 0.17 & 0.03 & 0.5 \\
Modified Clinoptilolite & 85.5 & 9.7 & 0.1 & 0.4 & 3.9 & 0.1 & 0.02 & 0.2 & 0.02 & 0.06 \\
S/ C & 76.04 & 15.5 & 1.02 & 0.37 & 4.2 & 0.08 & 2.6 & 0.17 & 0.01 & 0.01 \\
\hline
\end{tabular}

\subsection{Characterization of SAPO-34/Clinoptilolite}

\subsubsection{XRD analysis}

XRD spectrograms of the natural Clinoptilolite, modified Clinoptilolite with $\mathrm{HNO}_{3}$, SAPO-34 and S/C nanocomposite are represented in Fig. 2. The structure of natural zeolite sample complies well with the literature [32, 39]. The structure of Clinoptilolite changed and crystallinity of the Clinoptilolite decreased during the ion exchange process. The characteristic peaks of natural Clinoptilolite were observed at $2 \theta=9.82^{\circ}, 22.37^{\circ}, 24^{\circ}, 27.8^{\circ}, 29.58^{\circ}$ and 30.5 . For the modified Clinoptilolite, the peaks were at $2 \theta=21.41^{\circ}, 22.49^{\circ}, 27.02^{\circ}, 28.8^{\circ}, 30.5^{\circ}$ and $31.5^{\circ}$. The simultaneous existence of SAPO-34 and Clinoptilolite peaks in the XRD pattern of composite samples demonstrates the presence of both phases in the nanocomposite structure. Furthermore, as observed in XRD spectra of nanocomposites, ultrasonication in the synthesis process via sonochemical led to the formation of fully crystalline product. This is due to the fact that ultrasonication can effectively contribute to the improvement of nucleation stage, generation of a large number of nuclei in a lower level of supersatuarion as it has been indicated by other researchers $[40,41]$. The subsequent heat treatment allows growth of nuclei to reach a fully crystalline state. 


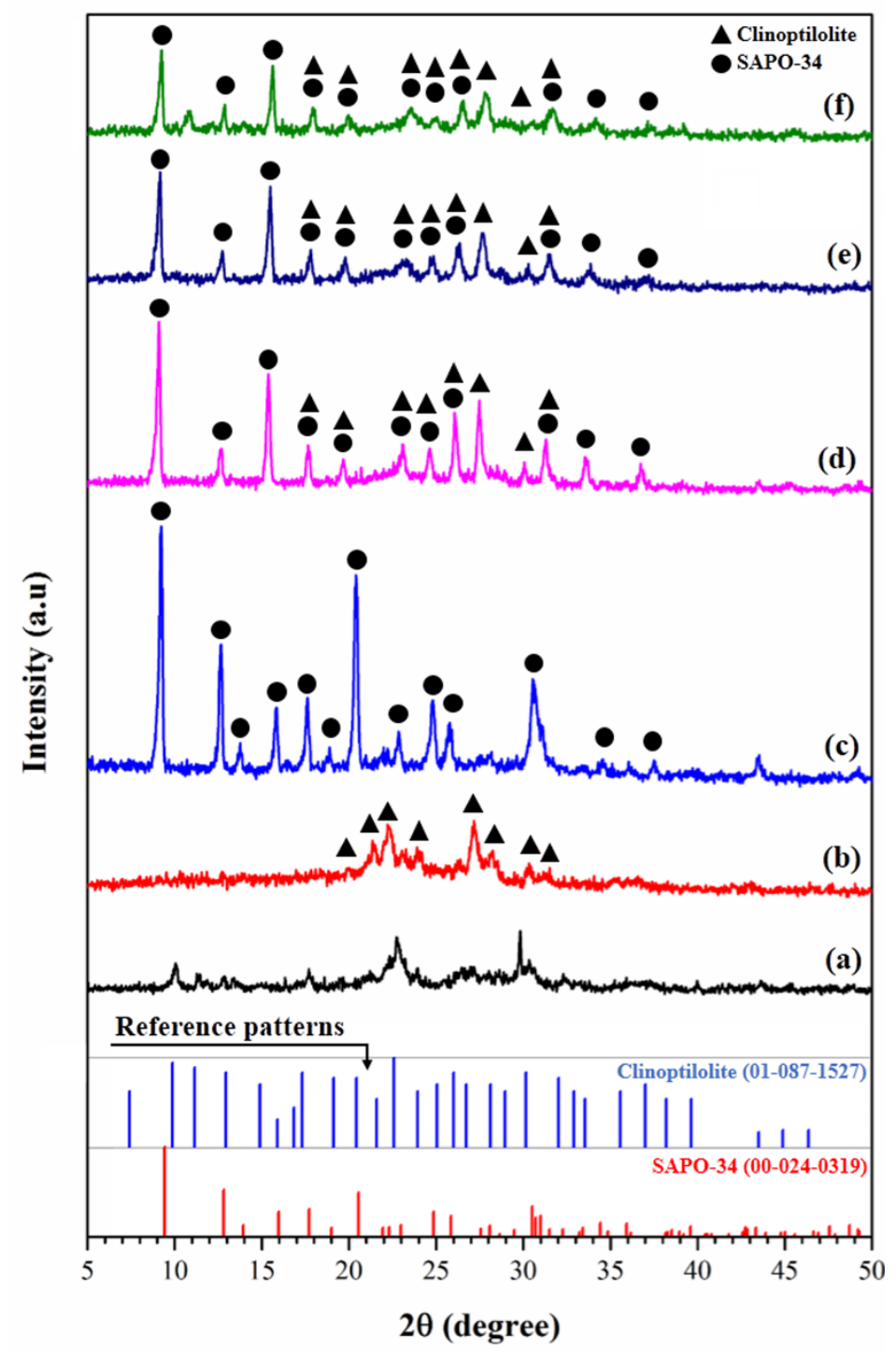

Figure 2. XRD patterns of (a) non-treated Clinoptilolite, (b) $\mathrm{HNO}_{3}$-treated Clinoptilolite, (c) SAPO-34, (d) S/C(50 wt. \%), (e) $\mathrm{S} / \mathrm{C}(70$ wt. \%) and (f) $\mathrm{S} / \mathrm{C}(90$ wt. \%).

\subsubsection{FESEM analysis}

Field Emission Scanning Electron Microscopy (FESEM) was used to reveal structure of the synthesized samples and the targeted core-shell structure in S/C nanocomposite. According to Fig. 3 (a) and (b) natural Clinoptilolite has rough and leaf-like surface with a dense structure while Fig. 3 (c) and (d) shows surface of Modified Clinoptilolite treated with $\mathrm{HNO}_{3}$ which has more smooth and sheet like surface. It is believe that as result of ion exchange and evacuation of 
extra ions on the structure of natural Clinoptilolite, modified Clinoptilolite structure is being smoother. Also, Fig. 4 (a) indicates morphology of SAPO-34 with a smooth and regular polyhedral morphology with approximately $2 \mu \mathrm{m}$ in size. FESEM results indicate formation of core-shell structure of nanocomposite due to grow of SAPO-34 crystal on the modified Clinoptilolite as support for active phase. Ultrasonic assisted hydrothermal procedure leads to the small size of the SAPO-34 because of better nucleation cites and controlled crystal growth [4143]. However, Fig. 4 (b), (c) and (e) shows synthesized S/C nanocomposite structure with hydrothermal method, thus S/C nanocomposite crystals has about $2 \mu \mathrm{m}$ diameter while Fig. 4 (d) and (f) indicates S/C that prepared with ultrasound assisted hydrothermal method has lower grain size with about $80 \mathrm{~nm}$. Accordingly, assisted hydrothermal method is an effective method for fairly homogeneous dispersion of Clinoptilolite in nanocomposite while hydrothermal method results into agglomeration of Clinoptilolite in nanocomposite. Also, as discussed above, ultrasound assisted method has impact in controlling the size of SAPO-34 too.
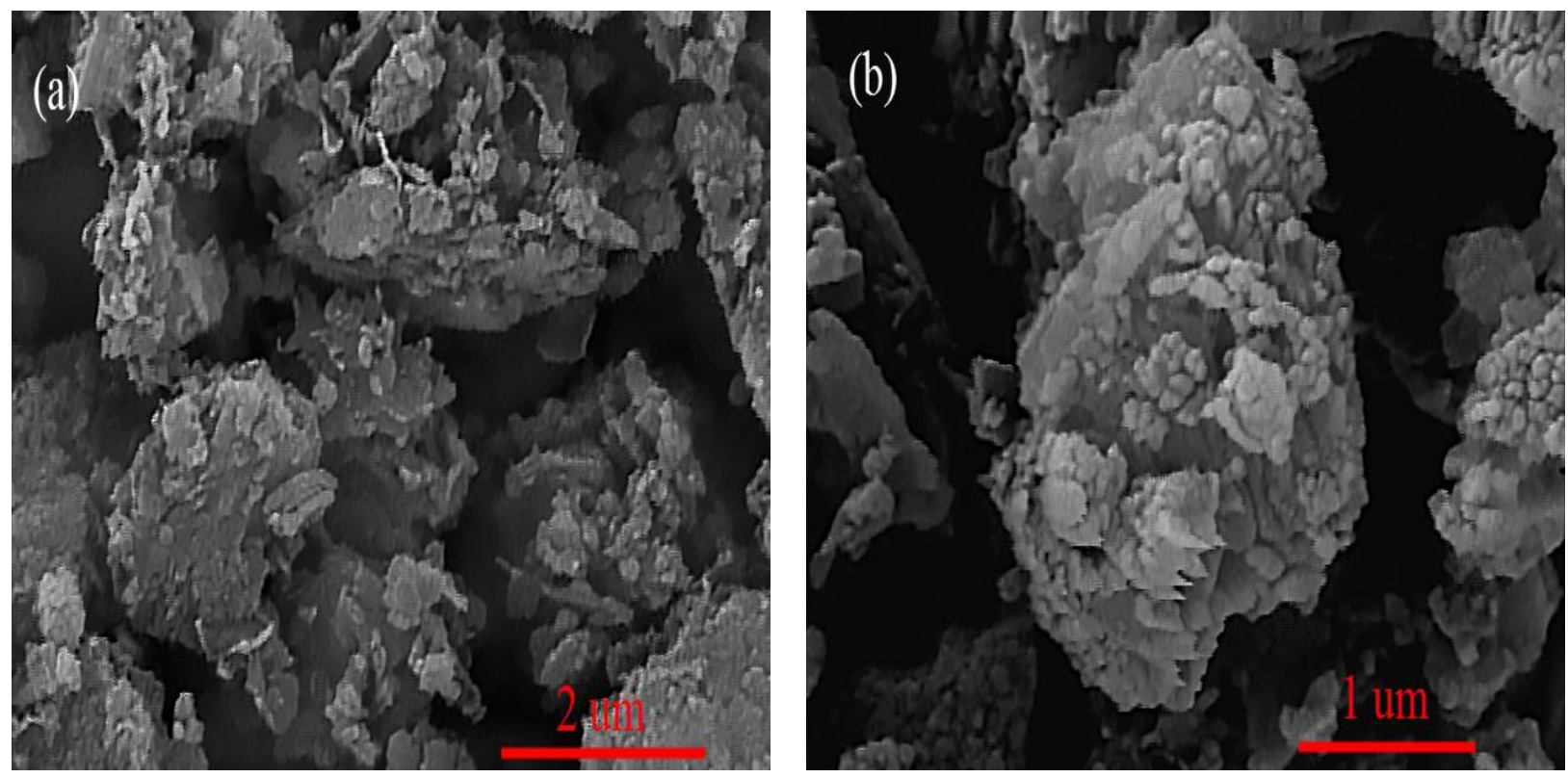

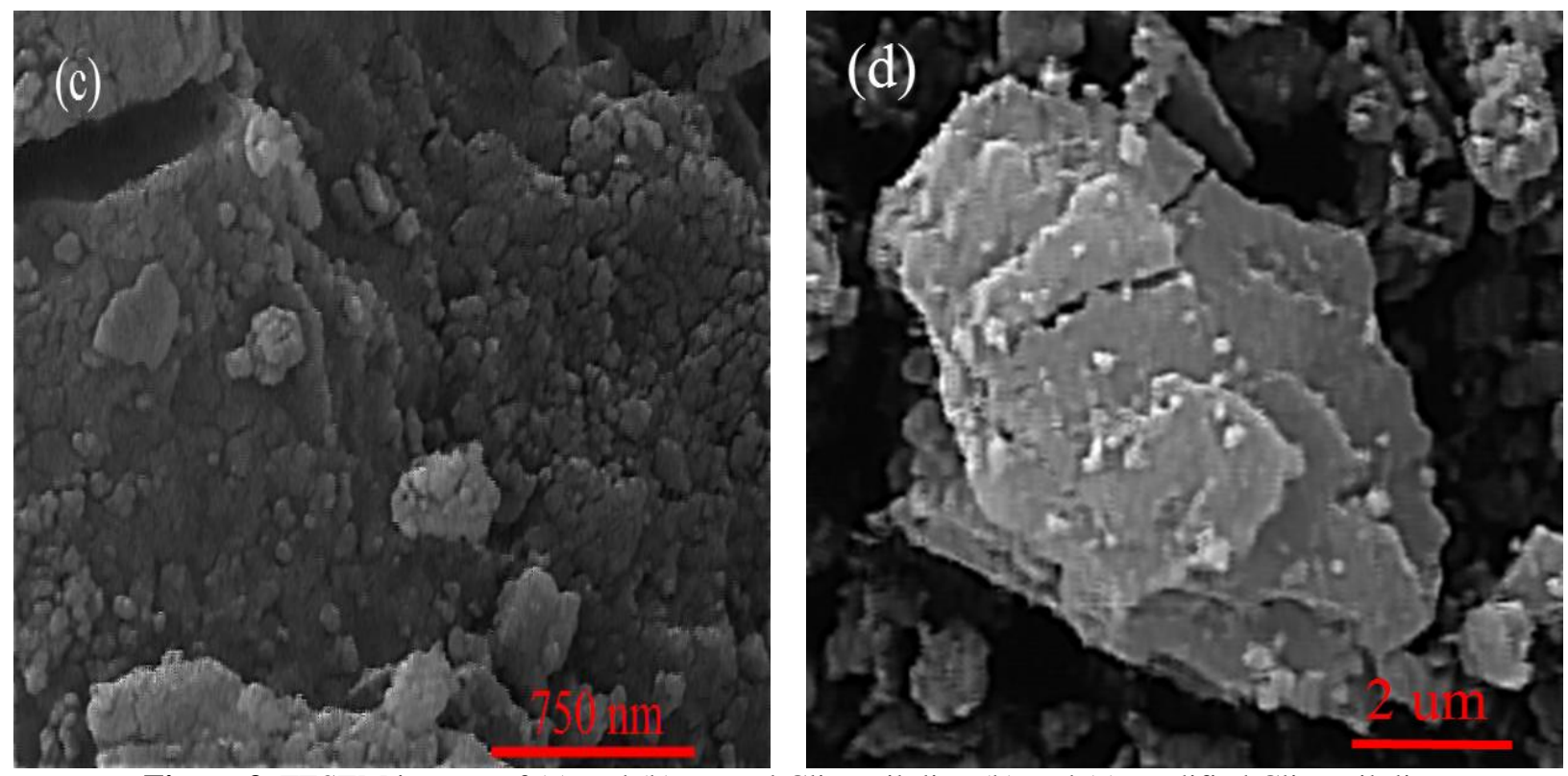

Figure 3. FESEM images of (a) and (b) natural Clinoptilolite, (b) and (c) modified Clinoptilolite.
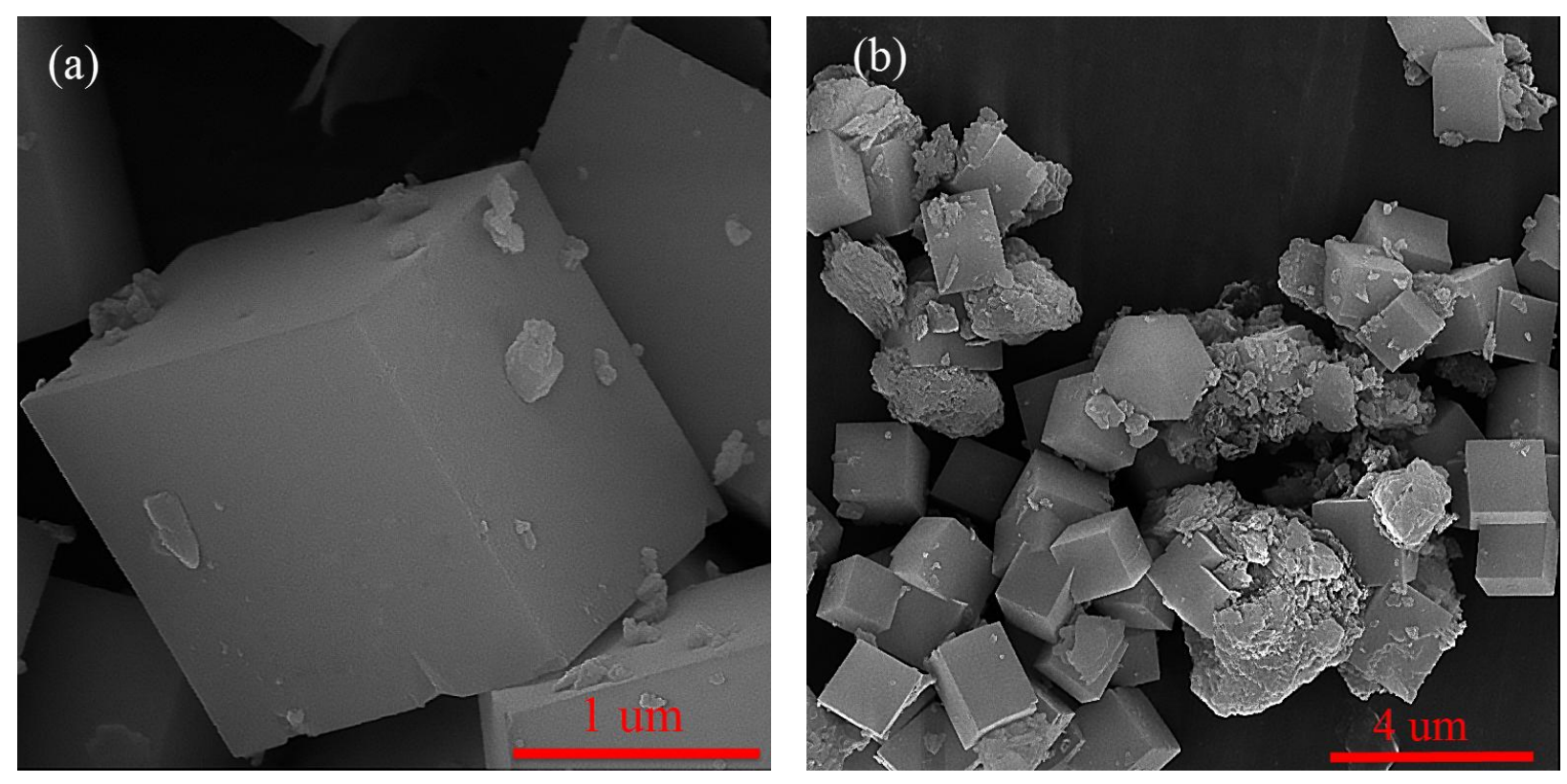

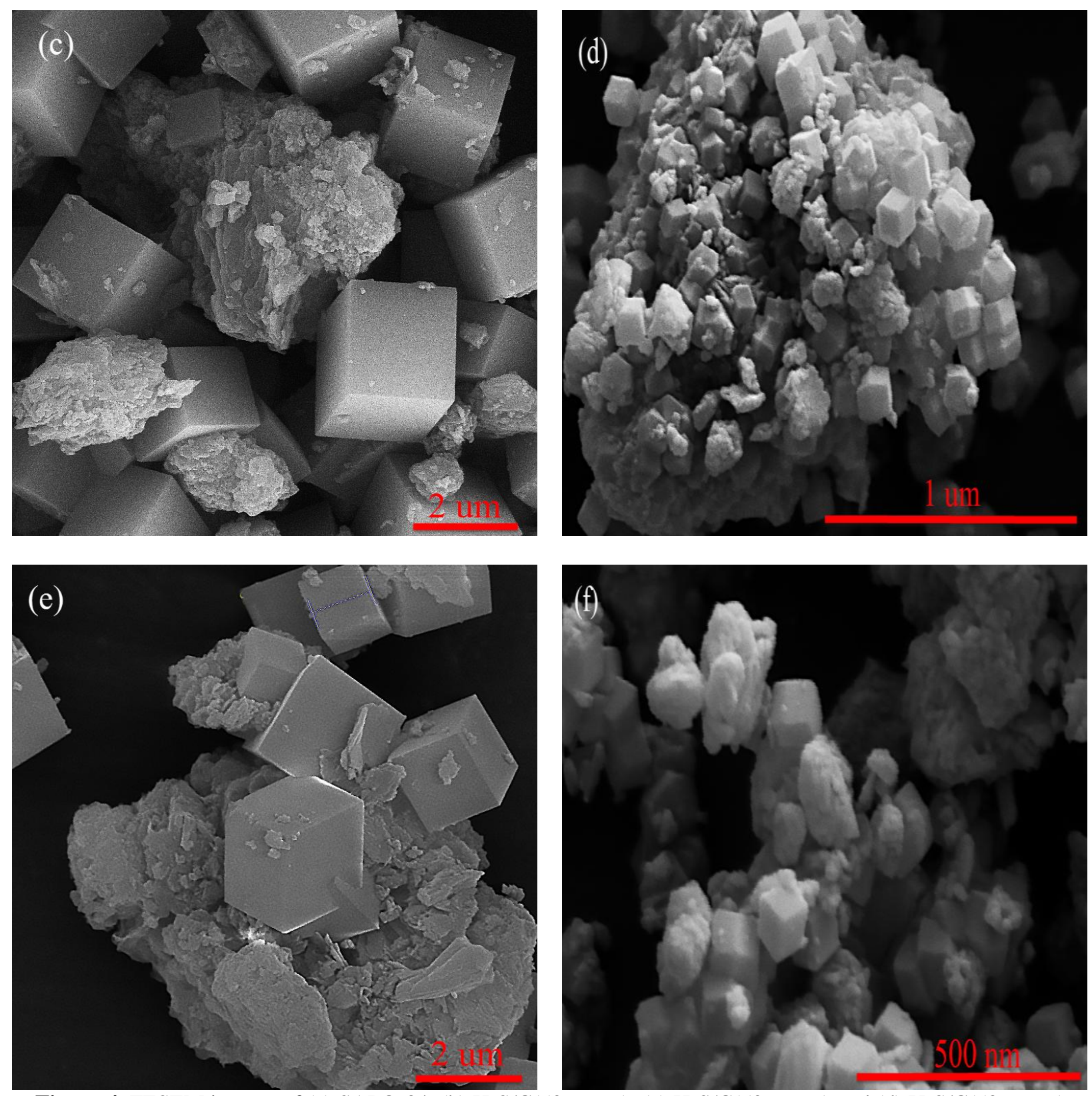

Figure 4. FESEM images of (a) SAPO-34, (b) H-S/C(50 wt. \%), (c) H-S/C(50 wt. \%) and (d) U-S/C(50 wt. \%), (e) $\mathrm{H}-\mathrm{S} / \mathrm{C}(70$ wt. \%) and (f) U-S/C(70 wt. \%). (H: Hydrothermal, U: ultrasonic).

\subsubsection{TEM analysis}

Figure 5 illustrates the TEM micrographs of S/C nanocomposite catalyst at different magnifications. The Clinoptilolite acts as a suitable surrounding material in which the SAPO-34 can easily grow. As seen in this Fig. 5 (a), the resultant leads to fabrication of the S/C core/shell 
nanocomposite catalyst with hierarchical structure containing in-plane and inter-layer micro-, meso-, and macropores, which is in good accordance with SEM and BET results. Furthermore, the lattice fringes interconnected between core and shell are obviously shown in magnified image (Figs. 5 (c) and (d)).
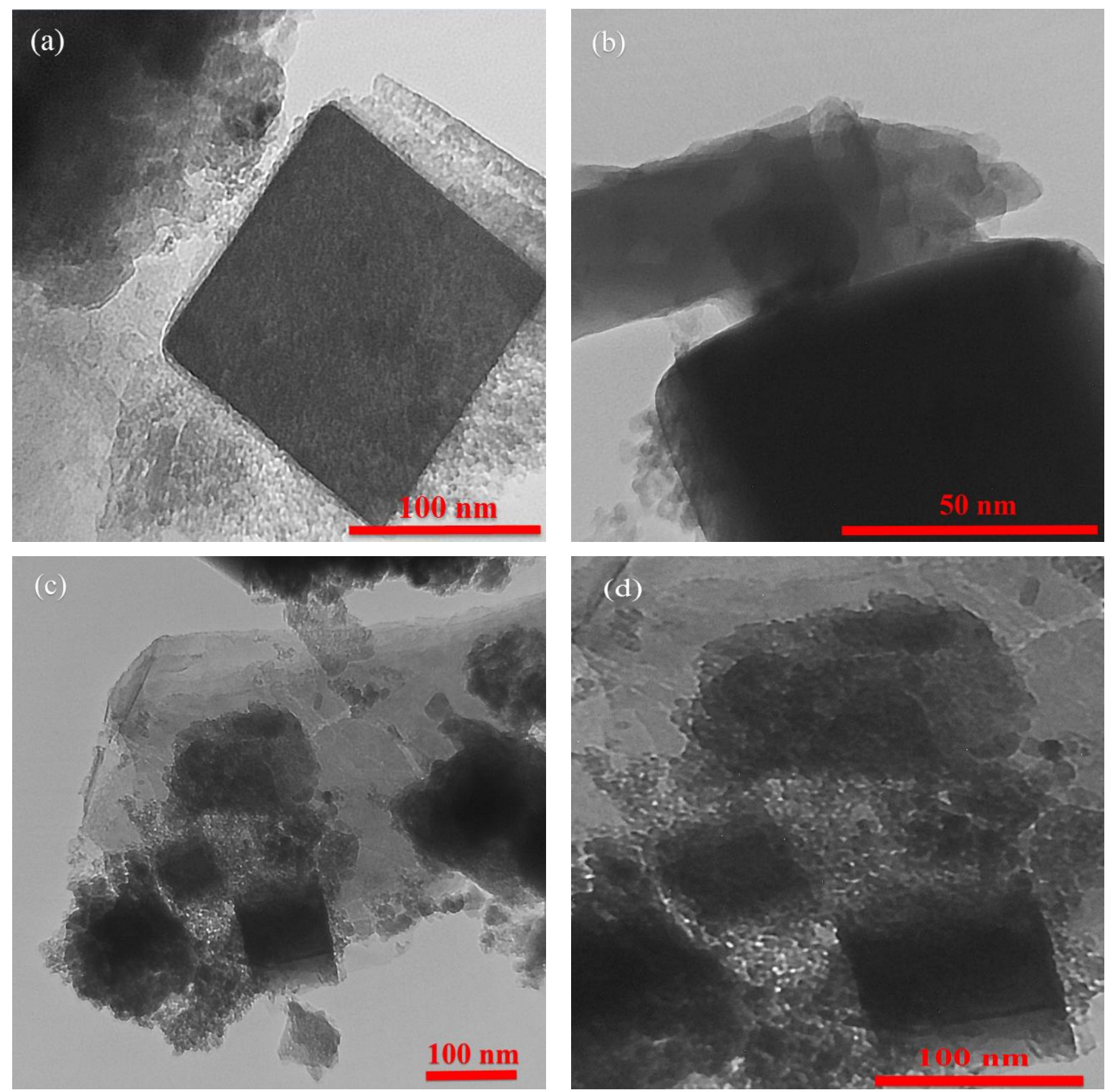

Figure 5. TEM images of S/C nanocomposite at different magnifications. 
As schematically shown in Fig. 6, Clinoptilolite particles interconnected to the SAPO-34 catalyst surface and as a role of matrix, they provide the suitable substrates for the growth of nano crystals. These particles lead to decomposition of nanocatalysts from each other and enhancement of their surface area. Furthermore, they cause interconnection of micropores, mesopores and macropores due to formation of hierarchical structure. This specific structure increases the mass transfer during chemical reactions. This could be related to cavitation bubbles acting as nuclei for crystal growth and disruption for the nuclei present within the medium thus increasing the number of nuclei in the medium. However, collapsing of bubbles in acoustic cavitation take place in less than a nanosecond and so, subsequent high rate of temperature decreases $(1011 \mathrm{~K} / \mathrm{s})$ preventing the organization and agglomeration of particles [41].

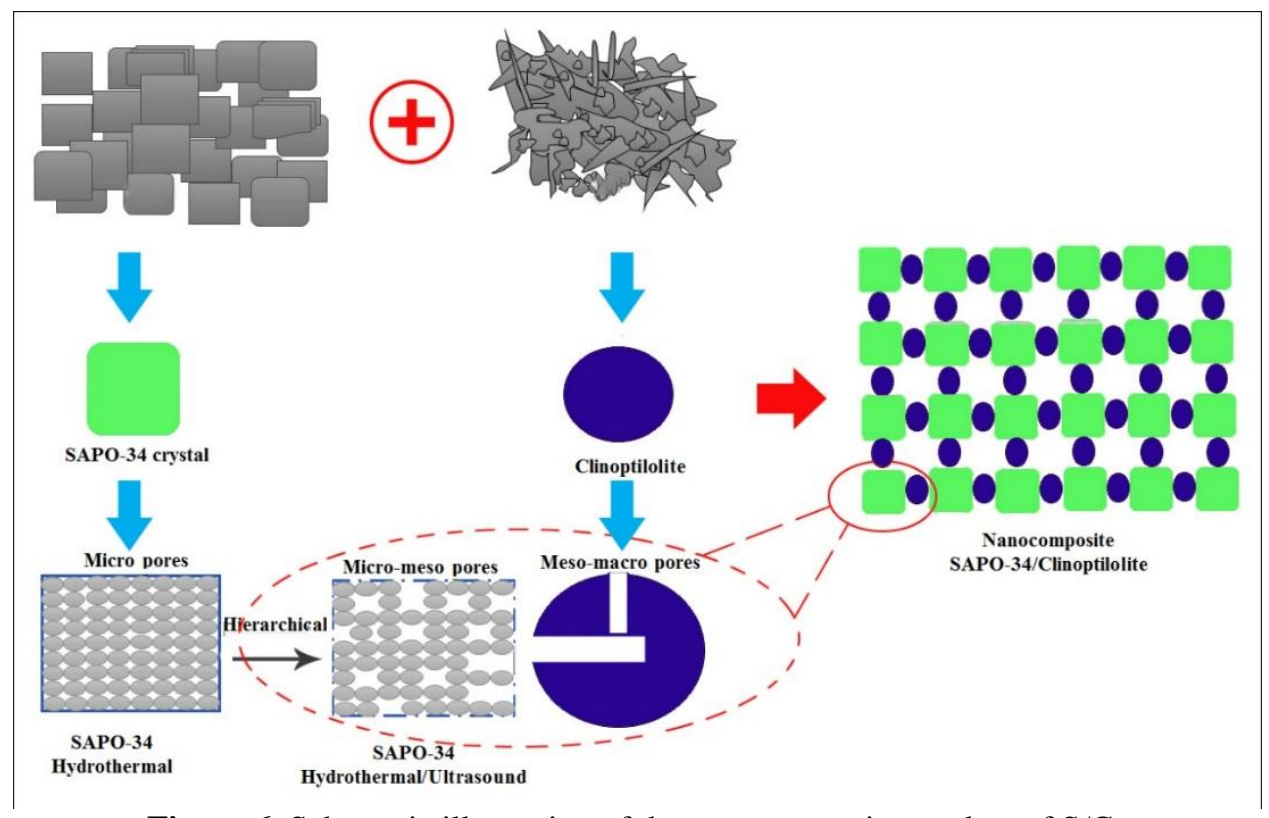

Figure 6. Schematic illustration of the nanocomposite catalyst of S/C.

\subsubsection{FTIR analysis}


FTIR spectroscopy was performed to identify any changes in the structure of S/C nanocomposites compared to their primary structure. Figure 7 shows FTIR spectra of natural zeolite, modified Clinoptilolite and SAPO-34/Clinoptilolite. The main characteristic bands of natural Clinoptilolite are at the wavelengths of $470 \mathrm{~cm}^{-1}, 607 \mathrm{~cm}^{-1}, 796 \mathrm{~cm}^{-1}, 1070 \mathrm{~cm}^{-1}, 1434$ $\mathrm{cm}^{-1}, 1632 \mathrm{~cm}^{-1}, 3436 \mathrm{~cm}^{-1}$ and $3617 \mathrm{~cm}^{-1}$. The appearance of a peak centered at $470 \mathrm{~cm}^{-1}$ in composite spectrum is attributed to stretching vibration of Al-O. Moreover, the peak at $670 \mathrm{~cm}^{-1}$ is ascribed to vibration of the external linkage of the tetrahedral. The bands at $796 \mathrm{~cm}^{-1}$ and 1070 $\mathrm{cm}^{-1}$ are assigned to $\mathrm{Si}-\mathrm{O}-\mathrm{Si}$ bonds, while the intense band at $3436 \mathrm{~cm}^{-1}$ is attributed to the stretching vibration of $\mathrm{O}-\mathrm{H}$ and $\mathrm{N}-\mathrm{H}$ bonds. The $\mathrm{Si}-\mathrm{O}(\mathrm{Si})$ and $\mathrm{Si}-\mathrm{O}(\mathrm{Al})$ stretching bands $(\mathrm{T}-\mathrm{O}-$ $\mathrm{T}$ bond) shift from $1070 \mathrm{~cm}^{-1}$ to higher wavenumbers $1093 \mathrm{~cm}^{-1}$ due to the loosing of $\mathrm{Al}^{3+}$ cations (dealumination of zeolite framework) during $\mathrm{HNO}_{3}$ modification and the change in the bond strength and $\mathrm{Si}-\mathrm{O}-\mathrm{Si}$ angle $[44,45]$. The bands at $1630 \mathrm{~cm}^{-1}$ and $3620 \mathrm{~cm}^{-1}$ are related to deformation vibration of absorbed water and acidic hydroxyls $\mathrm{Si}-\mathrm{O}(\mathrm{H})-\mathrm{A}$ respectively.

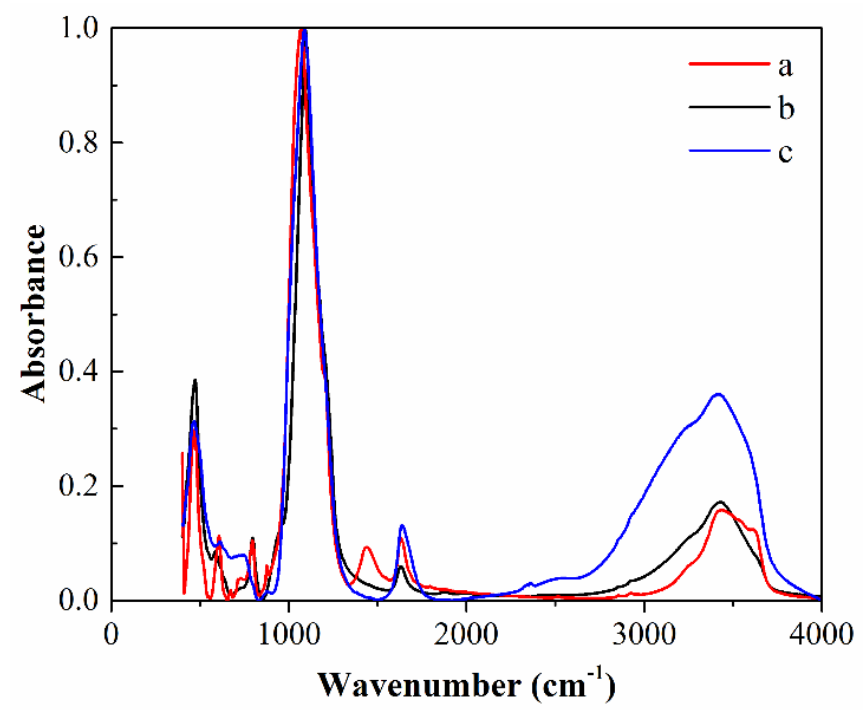

Figure 7. FT-IR spectra of (a) natural Clinoptilolite, (b) modified Clinoptilolite and (c) S/C. 


\subsubsection{Textural properties}

The BET area and pore volume of the calcined nanocatalysts are listed in Table 2. The sample of natural Clinoptilolite does not possess microporous structure, which was observed in acid treated of Clinoptilolite. However, the results highlight that the natural Clinoptilolite and protonated Clinoptilolite agglomerates are mesoporous. During $\mathrm{HNO}_{3}$ treatment surface area of natural Clinoptilolite increases from 20.07 to $187.8 \mathrm{~m}^{2} / \mathrm{g}$.

As a result of protonation, mesopore volume increases from 0.067 to $0.116 \mathrm{ml} / \mathrm{g}$ due to thermal treatment of zeolite particles. Reduction of diffusion resistance due to increase of mesoporosity is highly desired for synthesized catalysts during reaction. According to Table 2 SAPO-34 catalyst that synthesized with ultrasound method has more mesoporosity compared to conventional hydrothermal method. Furthermore, S/C shows higher mesoporosity due to composite which has $0.22 \mathrm{ml} / \mathrm{g}$ Mesopore volume while SAPO-34 has $0.27 \mathrm{ml} / \mathrm{g}$ Mesopore volume. However, results suggest that ultrasound method is an effective method to increase the mesoporosity of synthesized catalysts.

Table 2. Textual properties of SAPO-34, Clinoptilolite, S/C.

\begin{tabular}{|c|c|c|c|c|c|c|c|}
\hline \multirow{2}{*}{ Nomenclature } & \multirow{2}{*}{ Synthesis Method } & \multicolumn{2}{|c|}{$\begin{array}{l}\text { Surface area } \\
\left(\mathrm{m}^{2} / \mathrm{g}\right)\end{array}$} & \multicolumn{2}{|c|}{$\begin{array}{c}\text { Pore } \\
\text { volume }(\mathrm{ml} / \mathrm{g})\end{array}$} & \multicolumn{2}{|c|}{$\begin{array}{l}\text { Acid amount } \\
(\mathrm{mmol} / \mathrm{g})\end{array}$} \\
\hline & & $\mathrm{S}_{\text {micro }}$ & $\mathrm{S}_{\text {total }}$ & $\mathrm{V}_{\text {micro }}$ & $\mathrm{V}_{\text {total }}$ & $\begin{array}{l}\text { Weak } \\
\text { acidity }\end{array}$ & $\begin{array}{l}\text { Strong } \\
\text { acidity }\end{array}$ \\
\hline CL (n) & Natural & 0 & 20.07 & 0 & 0.067 & 1.3 & 0 \\
\hline $\mathrm{C}(\mathrm{m})$ & Modified $\left(\mathrm{HNO}_{3}\right.$-treated) & 17 & 187.8 & 0.019 & 0.135 & 1.08 & 0.35 \\
\hline $\mathrm{S}$ & Hydrothermal & 286.3 & 377.8 & 0.19 & 0.29 & 0.88 & 0.91 \\
\hline $\mathrm{S}$ & Hydrothermal/Ultrasound & 173.28 & 453.7 & 0.13 & 0.35 & 0.78 & 1.01 \\
\hline $\mathrm{S} / \mathrm{C}(\mathrm{m})$ & Hydrothermal/Ultrasound & 203.5 & 490 & 0.15 & 0.42 & 0.175 & 0.101 \\
\hline
\end{tabular}

C: Clinoptilolite, S: SAPO-34 


\subsection{6. $\mathrm{NH}_{3}$-TPD characterization}

$\mathrm{NH}_{3}$-TPD results are displayed in Fig. 8 which indicate the nature and distribution of the acid sites on the as-synthesized catalysts. Obviously, there are two acid site for all of synthesized catalysts, desorption of ammonia at low and high temperature attributed to weak and strong acidity respectively.

Thus, $\mathrm{NH}_{3}$-TPD for SAPO-34 indicate two acid sites at 200 and $480{ }^{\circ} \mathrm{C}$ with 0.8 and 1.09 mmol $\mathrm{NH}_{3} / g r$. On the other hand, natural Clinoptilolite and modified Clinoptilolite have a weak and strong acid site but with different intensity and concentration. Natural Clinoptilolite catalyst has only a weak acid site at $210{ }^{\circ} \mathrm{C}$, in contrast to modified Clinoptilolite catalyst that has two acid site at 207 and $620{ }^{\circ} \mathrm{C}$. Furthermore, S/C catalyst has the strongest acid site compared to the other samples duo to the modification of its structure and according to $\mathrm{NH}_{3}$-TPD has most strong acid site in comparison to the other samples while strong acid site of S/C nanocomposite catalyst shifted to $725^{\circ} \mathrm{C}$ with the same weak acid site as other samples. The summarized information of the acidity of catalysts is given in Table 2 .

Suitable acidity is key properties for MTO process. Weak acid sites can shift methanol to dimethyl ether (DME) only and completing reaction occur on strong acid sites where on this sites DME change to light olefins such as ethylene or propylene. Thus, all of catalyst has similar manner at weak acid sites with the acid site around $200{ }^{\circ} \mathrm{C}$ for all samples but Fig. 8 shows change in strong acid site where shifted around 480 to $725{ }^{\circ} \mathrm{C}$ for SAPO-34 to S/C nanocomposite samples. 


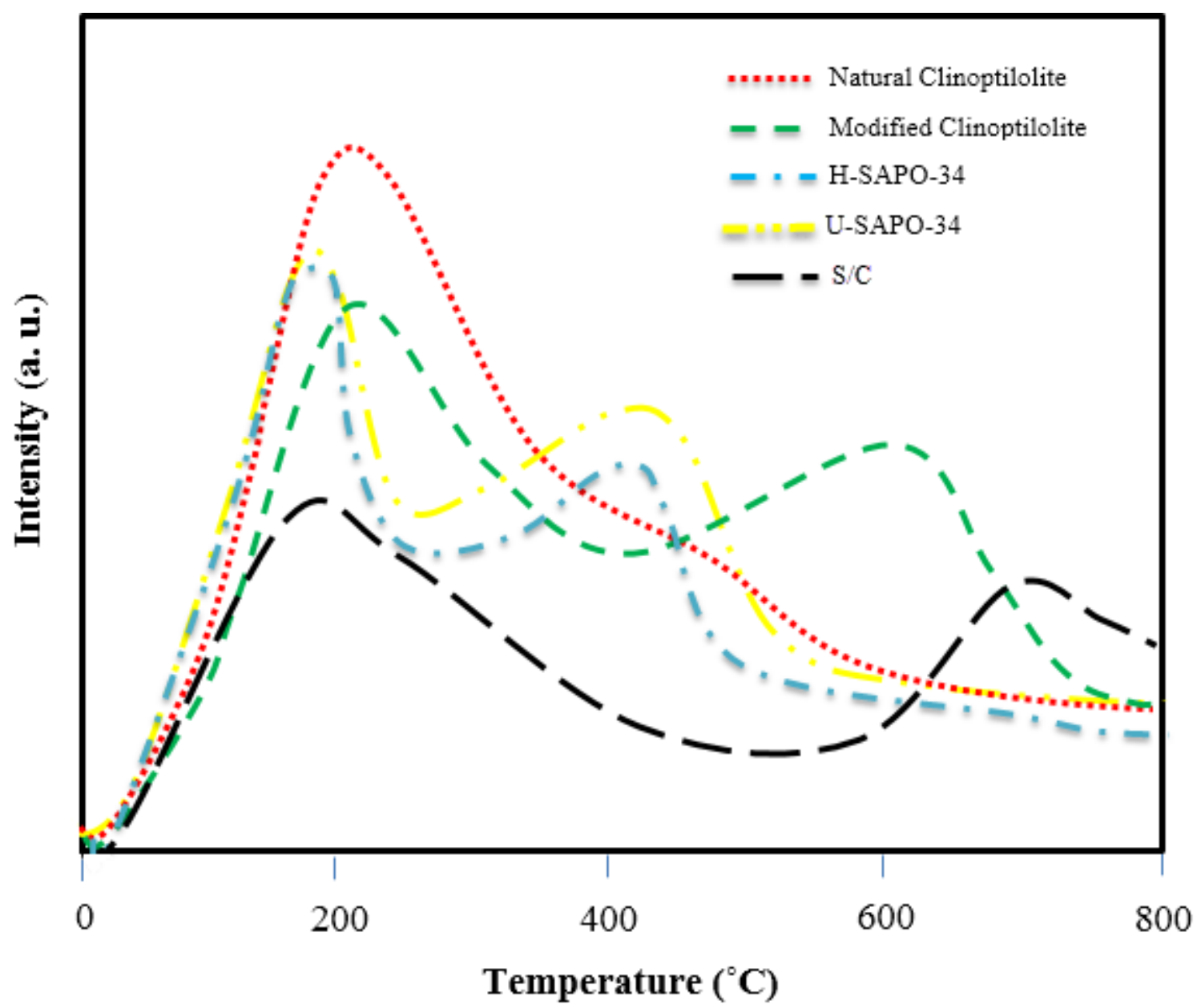

Figure 8. $\mathrm{NH}_{3}$-TPD patterns of different samples: natural Clinoptilolite, modified Clinoptilolite, H-SAPO-34. USAPO-34 and S/C.

\subsection{Catalyst performance}

The catalytic activity of prepared samples was studied at $723 \mathrm{~K}$ with a feed WHSV of $4.5 \mathrm{~h}^{-1}$. Catalytic performance analyses of all prepared samples were carried out in a differential -reactor for methanol conversion to olefins and the results were compared with those of individual SAPO-34, Clinoptilolite and physical mixture-derived catalysts (Figs. 9 and 10). All binary structures performed better than Clinoptilolite and SAPO-34 single structure catalyst. Nanocomposite catalyst showed higher conversion and propylene selectivity than physical mixture. 


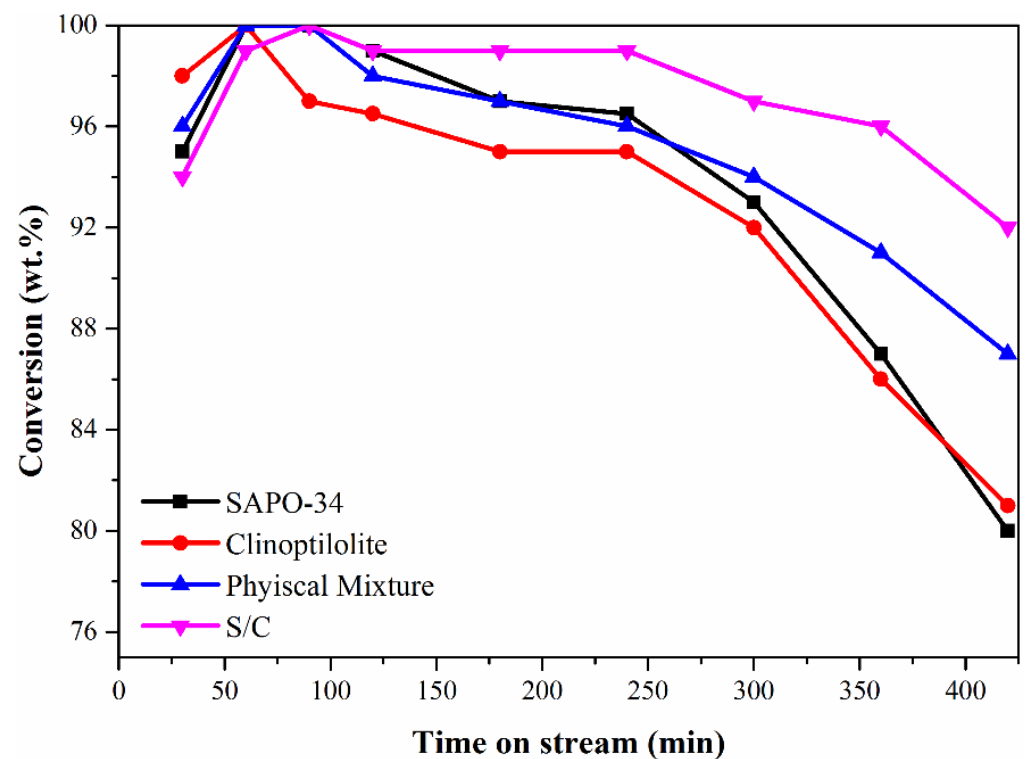

Figure 9. Methanol conversion over the SAPO-34, Clinoptilolite, physical mixture and nanocomposite S/C catalysts. Reaction conditions: Catalyst $=0.5 \mathrm{~g}, 450^{\circ} \mathrm{C}, \mathrm{WHSV}=4.5 \mathrm{~h}^{-1}$, Feed: methanol in water $(20 \mathrm{vol} . \%)$.

As presented in Fig. 9, the conversion profiles of the samples in the MTO reaction vary considerably according to their structure in terms of deactivation behavior. In all of them, the methanol conversion increases with time on stream, and after about $60 \mathrm{~min}$ the methanol conversion remains at almost $100 \%$. Induction period in the early time on stream (TOS) leads to incomplete conversion of methanol $[41,46,47]$ that can be explained through hydrocarbon pool (HP) mechanism. Haw and Kolboe reported that cyclic organic species such as hexamethylbenzene (HMB) play the role of the reaction centers for light olefins production as MTO reaction proceeds by a HP mechanism $[18,48]$. Accordingly, the time for the formation of these cyclic organic species causes the induction period, i.e. an increase in activity before maximum conversion. However, the small cage size of the SAPO-34 molecular sieve causes the formation of HMB in the cages works which serve as a diffusion barrier for methanol and lower olefins. Thus, it is expected that the growth of the active intermediates and enhancement of HMB 
concentration increase the methanol conversion [48]. Aforementioned common feature of the MTO reaction is related to the buildup of the HP, which is essential for catalytic activity [41, 46]. Although methanol conversion of SAPO-34 from $60 \mathrm{~min}$ to $260 \mathrm{~min}$ is high, it is rapidly deactivated due to coke formation. Modified Clinoptilolite shows good performance at the beginning of the reaction but it is rapidly deactivated as SAPO-34. This is because Clinoptilolite contains meso and macro pores that produces heavy hydrocarbons and consequently produced light olefins which diminishes as time elapses.

Methanol conversion of physical mixture is similar to that of SAPO-34 from 60 min to 300 min. However, it is deactivated very slowly in contrast to the SAPO-34 and modified Clinoptilolite. Nanocomposite of $\mathrm{S} / \mathrm{C}$ shows better performance than other samples and maintains this performance for a longer time. Moreover, high deactivation rate observed in Clinoptilolite and SAPO-34 does not happen when nanocomposite S/C is used as catalyst. Accordingly, it guaranties better performance of nanocomposite for a longer time. High performance of nanocomposite $\mathrm{S} / \mathrm{C}$ can be related to high surface area in nano-scale and better distribution of particles because of ultrasound waves leading to separation of the particles and uniform distribution of SAPO-34 among particles. Also, this high performance is because of contribution of Clinoptilolite phase itself in the MTO reaction.

Since methanol molecules finally adsorbed and converted on the acidic sites with respect to time on stream, the molecules product formed diffuse out of the pore structure [49]. The S/C nanocomposite catalyst converted rapidly and its activity (for example methanol conversion) lasts for over $420 \mathrm{~min}$, at a later time, its conversion rapidly reduces at the end of $280 \mathrm{~min}$. Figure 10 shows the product distribution with time on stream for the four catalysts samples. A high content of light olefins was obtained over the S/C nanocomposite catalyst. At the beginning of 
the reaction, SAPO-34 produces a considerable amount of light olefins but after 150 min amount of olefins decreases whereas S/C nanocomposite high olefins production lasts for 420 min and thereafter the production gradually reduces. Note that more propylene is produce and this higher production continues for a longer time.

At the beginning of the time on stream, the propylene/ethylene ratio is the same for all the catalysts, thereafter it decreases when the reaction is terminated. Propylene content decreases more rapidly than ethylene which can be related to the coking effect that reduces the pore size of SAPO-34. It prevents high production of hydrocarbons such as propylene [50-52] However, using nanocomposite causes high production of propylene in contrast to SAPO-34 [18]. Clinoptilolite as a binder separates SAPO-34 particles from each other and increases the surface area. Moreover, Clinoptilolite itself contributes in the reaction which produces more propylene. In the other hand, interconnection between micro, meso and macro pores probably causes higher production of propylene. As expected, modified Clinoptilolite exhibits activity and selectivity to light olefins due to its structure. However, its performance is inferior to those of the other samples. Physical mixture shows good performance in comparison to S/C nanocomposite, nevertheless high olefin productions more rapidly diminishes. Accordingly, the composite synthesized in this study might be a promising catalyst to meet a change of market demand for light olefin such as ethylene and propylene. 

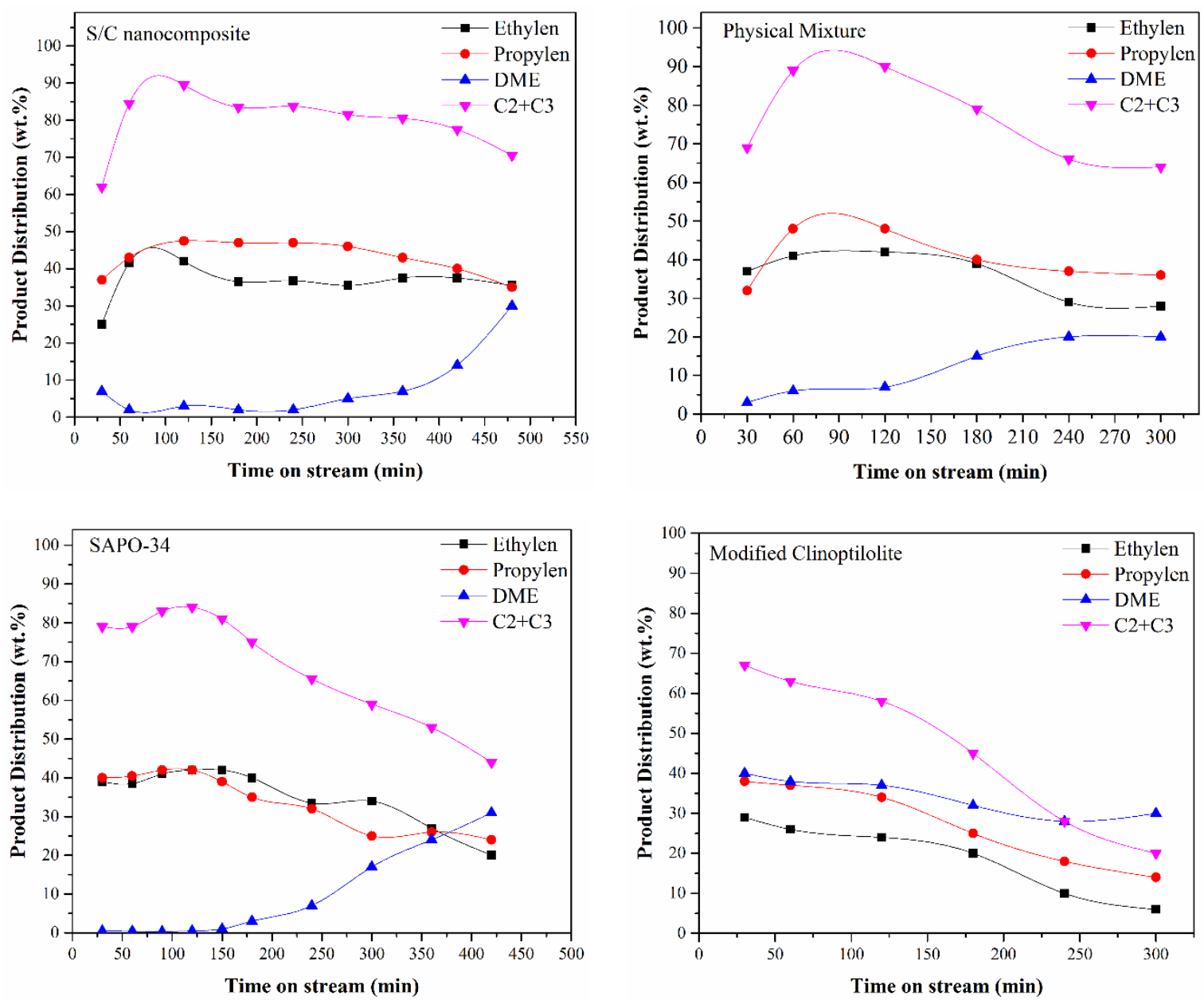

Figure 10. Product composition with time on stream over the SAPO-34, Clinoptilolite, physical mixture and S/C nanocomposite catalysts. Reaction conditions: Catalyst $=0.5 \mathrm{~g}, 450{ }^{\circ} \mathrm{C}, \mathrm{WHSV}=4.5 \mathrm{~h}^{-1}$, Feed: methanol in water (20 vol. \%).

\subsection{Performance Comparison}

The catalytic efficiency of the prepared catalyst was compared with those of some nanocomposites of SAPO-34 catalysts in the MTO reaction. The data in Table 3 shows that the nanocomposite of S/C catalyst gives a higher selectivity, and yields light olefins compared with other nanocomposite of SAPO-34 catalysts. Good performance of this catalyst could be related to acceleration of the reaction rate in the presence of Clinoptilolite as a binder, homogeneous 
disperse of particle due to ultrasonic wave, micro-meso- macroporous structure and the connected channels between SAPO-34 and Clinoptilolite.

Table 3. Comparison of performance of prepared nanocomposite catalyst and various reported nanocomposite of SAPO-34 catalysts.

\begin{tabular}{|c|c|c|c|c|c|c|c|}
\hline \multirow{2}{*}{ Nanocomposite catalyst } & \multirow{2}{*}{$\begin{array}{c}\mathrm{MeOH} \\
\text { conv. } \\
(\%)\end{array}$} & \multicolumn{4}{|c|}{$\begin{array}{c}\text { Product selectivity and } \\
\text { yield }(\%)\end{array}$} & \multirow{2}{*}{ Reaction conditions } & \multirow{2}{*}{ Ref } \\
\hline & & $c$ & & & & & \\
\hline ZSM-5/SAPO-34 & 97 & 40.5 & $\ldots$ & 38 & - & $\begin{array}{l}\text { MTO reaction, } 1.2 \mathrm{~g} \text { catalyst, } \\
\text { WHSV }=2.4 \mathrm{~h}^{-1}, \mathrm{~T}=400^{\circ} \mathrm{C}\end{array}$ & [1] \\
\hline ZSM-5/SAPO-34 & 100 & 26.6 & $\ldots$ & 29 & - & $\begin{array}{l}\text { MTO reaction, } 0.2 \mathrm{~g} \text { catalyst, } \\
\mathrm{WHSV}=1.6 \mathrm{~h}^{-1}, \mathrm{~T}=400^{\circ} \mathrm{C}\end{array}$ & [9] \\
\hline SAPO-34/ZrO & 100 & 40.2 & - & 36.1 & - & $\begin{array}{l}\text { DTO reaction, }, 0.2 \mathrm{~g} \text { catalyst, } \\
\text { WHSV }=3.54 \mathrm{~h}^{-1}, \mathrm{~T}=400^{\circ} \mathrm{C}\end{array}$ & [14] \\
\hline $\mathrm{SAPO}-34 / \alpha-\mathrm{Al}_{2} \mathrm{O}_{3}$ & 99.5 & 39.2 & - & 41.5 & - & $\begin{array}{l}\text { DTO reaction, }, 0.2 \mathrm{~g} \text { catalyst, } \\
\text { WHSV }=3.54 \mathrm{~h}^{-1}, \mathrm{~T}=400^{\circ} \mathrm{C}\end{array}$ & [14] \\
\hline ZSM-5/SAPO-34 & 100 & 10 & 4 & 80 & 31 & $\begin{array}{l}\text { MTO reaction, } 0.5 \mathrm{~g} \text { catalyst, } \\
\text { WHSV }=4 \mathrm{~h}^{-1}, \mathrm{~T}=600^{\circ} \mathrm{C}\end{array}$ & [36] \\
\hline HZSM-5/SAPO-34 & 100 & - & 26.6 & - & 32.3 & $\begin{array}{c}\text { ethanol to propylene reaction, } 0.5 \\
\mathrm{~g} \text { catalyst, } \mathrm{T}=500^{\circ} \mathrm{C}\end{array}$ & [38] \\
\hline $\mathrm{S} / \mathrm{C}$ & 100 & 42 & $\ldots$ & 47.5 & - & $\begin{array}{l}\text { MTO reaction, } 0.5 \mathrm{~g} \text { catalyst, } \\
\text { WHSV }=4.5 \mathrm{~h}^{-1}, \mathrm{~T}=450^{\circ} \mathrm{C}\end{array}$ & $\begin{array}{l}\text { This } \\
\text { work }\end{array}$ \\
\hline
\end{tabular}

\section{Conclusions}

S/C nanocomposites were synthesized through hydrothermal assistance ultrasonic methods and used in MTO reaction. Due to easy accessibility and low price of Clinoptilolite natural zeolite, it was blended with expensive synthesized SAPO-34 catalyst to make a nanocomposite with high economical margin. In fact, adding Clinoptilolite decreases the amount of SAPO-34 in nanocomposite and in turn reduces the total cost and Clinoptilolite presence accelerates MTO reaction (by producing DME from Methanol). XRD, XRF, FT-IR, FESEM, TEM, $\mathrm{NH}_{3}-\mathrm{TPD}_{\text {and }}$ 23 
$\mathrm{N}_{2}$ isotherm analysis results highlighted that synthesized composites are superior to their initial state. Notably, it was shown that the synthesized nanocomposite has the morphology with Clinoptilolite as the binder and SAPO-34 as the active component. Using $\mathrm{HNO}_{3}$-treatment, the specific surface area of natural zeolite increased obviously, whereas the crystallinity of the Clinoptilolite decreased. Furthermore, the FESEM analysis indicated that morphology of the Clinoptilolite changes with the modification of zeolite. The nanocomposite catalyst synthesized in this study is highly efficient in olefins production especially propylene by $45 \%$. The Catalytic lifetimes were also improved in compare with the free SAPO-34 in MTO process. S/C composite catalyst could be regarded as a promising MTO catalyst to meet a market demand for light olefin.

\section{Acknowledgements}

The authors gratefully acknowledge the financial supports from Iran National Science Foundation and National Petrochemical Company (NPC) of Iran. 


\section{References}

[1] F. Liu, X. Wang, F. Xu, Q. Lin, H. Pan, H. Wu, J. Cao, Fabrication and characterization of composites comprising (CHA) SAPO-34 with (MFI) ZSM-5 topologies and their catalytic performances on MTO reaction, Microporous and Mesoporous Materials (2016).

[2] S. Askari, R. Halladj, M. Sohrabi, Methanol conversion to light olefins over sonochemically prepared SAPO-34 nanocatalyst, Microporous and Mesoporous Materials 163 (2012) 334-342.

[3] A. Corma, From microporous to mesoporous molecular sieve materials and their use in catalysis, Chemical reviews 97 (1997) 2373-2420.

[4] R.M. Behbahani, A.S. Mehr, Studying activity, product distribution and lifetime of Sr promoted alkali modified low Si ZSM-5 catalyst in MTO process, Journal of Natural Gas Science and Engineering 18 (2014) 433-438.

[5] R. Khoshbin, M. Haghighi, N. Asgari, Direct synthesis of dimethyl ether on the admixed nanocatalysts of CuO-ZnO-Al2O3 and HNO3-modified clinoptilolite at high pressures: Surface properties and catalytic performance, Materials Research Bulletin 48 (2013) 767-777.

[6] S. Askari, R. Halladj, M. Nazari, Statistical analysis of sonochemical synthesis of SAPO-34 nanocrystals using Taguchi experimental design, Materials Research Bulletin 48 (2013) 1851-1856.

[7] N. Najafi, S. Askari, R. Halladj, Hydrothermal synthesis of nanosized SAPO-34 molecular sieves by different combinations of multi templates, Powder Technology 254 (2014) 324-330.

[8] F.M. Shalmani, S. Askari, R. Halladj, Microwave synthesis of SAPO molecular sieves, Reviews in Chemical Engineering 29 (2013) 99-122.

[9] H.-J. Chae, Y.-H. Song, K.-E. Jeong, C.-U. Kim, S.-Y. Jeong, Physicochemical characteristics of ZSM5/SAPO-34 composite catalyst for MTO reaction, Journal of Physics and Chemistry of Solids 71 (2010) 600-603.

[10] W. Dai, C.-M. Wang, M. Dyballa, G. Wu, N. Guan, L. Li, Z. Xie, M. Hunger, Understanding the early stages of the methanol-to-olefin conversion on H-SAPO-34, ACS Catalysis (2015).

[11] M. Nazari, G. Moradi, R.M. Behbahani, M. Ghavipour, Dry gel conversion as a suitable method for increasing the lifetime of SAPO-18 in MTO process, Journal of Natural Gas Science and Engineering 29 (2016) 337-344.

[12] P. Wang, A. Lv, J. Hu, J.a. Xu, G. Lu, The synthesis of SAPO-34 with mixed template and its catalytic performance for methanol to olefins reaction, Microporous and Mesoporous Materials 152 (2012) 178184.

[13] F.M. Shalmani, R. Halladj, S. Askari, Effect of contributing factors on microwave-assisted hydrothermal synthesis of nanosized SAPO-34 molecular sieves, Powder technology 221 (2012) 395-402.

[14] S.-G. Lee, H.-S. Kim, Y.-H. Kim, E.-J. Kang, D.-H. Lee, C.-S. Park, Dimethyl ether conversion to light olefins over the SAPO-34/ZrO 2 composite catalysts with high lifetime, Journal of Industrial and Engineering Chemistry 20 (2014) 61-67.

[15] L. Bonaccorsi, L. Calabrese, E. Proverbio, A. Frazzica, A. Freni, G. Restuccia, E. Piperopoulos, C. Milone, Synthesis of SAPO-34/graphite composites for low temperature heat adsorption pumps, Journal of Energy Chemistry 22 (2013) 245-250.

[16] Z. Lixiong, J. Mengdong, M. Enze, Synthesis of SAPO-34/ceramic composite membranes, Studies in Surface Science and Catalysis 105 (1997) 2211-2216.

[17] S. Askari, Z. Sedighi, R. Halladj, Rapid synthesis of SAPO-34 nanocatalyst by dry gel conversion method templated with morphline: Investigating the effects of experimental parameters, Microporous and Mesoporous Materials 197 (2014) 229-236. 
[18] S. Askari, R. Halladj, Effects of ultrasound-related variables on sonochemically synthesized SAPO-34 nanoparticles, Journal of Solid State Chemistry 201 (2013) 85-92.

[19] Z. Yinghuai, Application of ultrasound technique in the synthesis of methanofullerene derivatives, Journal of Physics and Chemistry of Solids 65 (2004) 349-353.

[20] M. Barzegar, A. Habibi-Yangjeh, M. Behboudnia, Ultrasonic-assisted preparation and characterization of CdS nanoparticles in the presence of a halide-free and low-cost ionic liquid and photocatalytic activity, Journal of Physics and Chemistry of Solids 71 (2010) 1393-1397.

[21] G.T. Kokotailo, C.A. Fyfe, Perspective: Zeolites; Unique materials for research and industry, Journal of Physics and Chemistry of Solids 50 (1989) 441-447.

[22] J. Kim, Y. Kim, J. Yoon, D. Park, H. Woo, Catalytic degradation of polypropylene: effect of dealumination of clinoptilolite catalyst, Polymer degradation and stability 75 (2002) 287-294.

[23] D. Verboekend, T.C. Keller, M. Milina, R. Hauert, J. Pérez-Ramírez, Hierarchy Brings Function: Mesoporous Clinoptilolite and L Zeolite Catalysts Synthesized by Tandem Acid-Base Treatments, Chemistry of Materials 25 (2013) 1947-1959.

[24] M. Sprynskyy, R. Golembiewski, G. Trykowski, B. Buszewski, Heterogeneity and hierarchy of clinoptilolite porosity, Journal of Physics and Chemistry of Solids 71 (2010) 1269-1277.

[25] J. Zheng, G. Wang, M. Pan, D. Guo, Q. Zhao, B. Li, R. Li, Hierarchical core-shell zeolite composite ZSM-5@ SAPO-34 fabricated by using ZSM-5 as the nutrients for the growth of SAPO-34, Microporous and Mesoporous Materials 206 (2015) 114-120.

[26] R. Miao, J. Yang, Y. Wu, J. Wang, Y. Nuli, W. Lu, Nanoporous silicon from low-cost natural clinoptilolite for lithium storage, RSC Advances 5 (2015) 56772-56779.

[27] R. Parton, L. Uytterhoeven, J. Martens, P. Jacobs, G. Froment, Synergism of ZSM-22 and Y zeolites in the bifunctional conversion of n-alkanes, Applied catalysis 76 (1991) 131-142.

[28] P.G. Smirniotis, L. Davydov, E. Ruckenstein, Composite zeolite-based catalysts and sorbents, Catalysis Reviews 41 (1999) 43-113.

[29] S.-C. Baek, Y.-J. Lee, K.-W. Jun, S.B. Hong, Influence of Catalytic Functionalities of Zeolites on Product Selectivities in Methanol Conversion, Energy \& Fuels 23 (2009) 593-598.

[30] T.K. Katranas, A.G. Vlessidis, V.A. Tsiatouras, K.S. Triantafyllidis, N.P. Evmiridis, Dehydrogenation of propane over natural clinoptilolite zeolites, Microporous and mesoporous materials 61 (2003) 189-198.

[31] R. Moreno-Tost, J. Santamaría-González, E. Rodríguez-Castellón, A. Jiménez-López, M.A. Autié, E. González, M.C. Glacial, C.D.I. Pozas, Selective catalytic reduction of nitric oxide by ammonia over Cuexchanged Cuban natural zeolites, Applied Catalysis B: Environmental 50 (2004) 279-288.

[32] Y. Zeng, H. Woo, G. Lee, J. Park, Removal of chromate from water using surfactant modified Pohang clinoptilolite and Haruna chabazite, Desalination 257 (2010) 102-109.

[33] M. Doula, A. Dimirkou, Use of an iron-overexchanged clinoptilolite for the removal of Cu< sup> $2+</$ sup $>$ ions from heavily contaminated drinking water samples, Journal of hazardous materials 151 (2008) 738-745.

[34] E. Ivanova, B. Koumanova, Adsorption of sulfur dioxide on natural clinoptilolite chemically modified with salt solutions, Journal of hazardous materials 167 (2009) 306-312.

[35] M. Sprynskyy, T. Ligor, M. Lebedynets, B. Buszewski, Kinetic and equilibrium studies of phenol adsorption by natural and modified forms of the clinoptilolite, Journal of hazardous materials 169 (2009) 847-854.

[36] M. Razavian, S. Fatemi, Synthesis and application of ZSM-5/SAPO-34 and SAPO-34/ZSM-5 composite systems for propylene yield enhancement in propane dehydrogenation process, Microporous and Mesoporous Materials 201 (2015) 176-189.

[37] C. Duan, X. Zhang, R. Zhou, Y. Hua, J. Chen, L. Zhang, Hydrothermally synthesized HZSM-5/SAPO-34 composite zeolite catalyst for ethanol conversion to propylene, Catalysis letters 141 (2011) 1821-1827. 
[38] C. Duan, X. Zhang, R. Zhou, Y. Hua, L. Zhang, J. Chen, Comparative studies of ethanol to propylene over HZSM-5/SAPO-34 catalysts prepared by hydrothermal synthesis and physical mixture, Fuel processing technology 108 (2013) 31-40.

[39] A. Olad, B. Naseri, Preparation, characterization and anticorrosive properties of a novel polyaniline/clinoptilolite nanocomposite, Progress in Organic Coatings 67 (2010) 233-238.

[40] J. Talebi, R. Halladj, S. Askari, Sonochemical synthesis of silver nanoparticles in Y-zeolite substrate, Journal of materials science 45 (2010) 3318-3324.

[41] S. Askari, R. Halladj, Ultrasonic pretreatment for hydrothermal synthesis of SAPO-34 nanocrystals, Ultrasonics sonochemistry 19 (2012) 554-559.

[42] M. Sayyah, E. Abbasi, Y. Lu, J. Abbasian, K.S. Suslick, Composite CaO-Based CO2 Sorbents Synthesized by Ultrasonic Spray Pyrolysis: Experimental Results and Modeling, Energy \& Fuels 29 (2015) 4447-4452.

[43] L. Yosefi, M. Haghighi, S. Allahyari, S. Ashkriz, The beneficial use of HCl-activated natural zeolite in ultrasound assisted synthesis of $\mathrm{Cu}$ /clinoptilolite-CeO2 nanocatalyst used for catalytic oxidation of diluted toluene in air at low temperature, Journal of Chemical Technology and Biotechnology 90 (2015) 765-774.

[44] W. Mozgawa, The influence of some heavy metals cations on the FTIR spectra of zeolites, Journal of Molecular Structure 555 (2000) 299-304.

[45] A. De Man, S. Ueda, M. Annen, M. Davis, R. Van Santen, The stability and vibrational spectra of three-ring containing zeolitic silica polymorphs, Zeolites 12 (1992) 789-800.

[46] H. Hajfarajollah, S. Askari, R. Halladj, Effects of micro and nano-sized SAPO-34 and SAPO-5 catalysts on the conversion of methanol to light olefins, Reaction Kinetics, Mechanisms and Catalysis 111 (2014) 723-736.

[47] B.M. Lok, C.A. Messina, R.L. Patton, R.T. Gajek, T.R. Cannan, E.M. Flanigen, Silicoaluminophosphate molecular sieves: another new class of microporous crystalline inorganic solids, Journal of the American Chemical Society 106 (1984) 6092-6093.

[48] U. Lohse, R. Bertram, K. Jancke, I. Kurzawski, B. Parlitz, E. Löuffler, E. Schreier, Acidity of aluminophosphate structures. Part 2.-Incorporation of cobalt into CHA and AFI by microwave synthesis, Journal of the Chemical Society, Faraday Transactions 91 (1995) 1163-1172.

[49] A. Izadbakhsh, F. Farhadi, F. Khorasheh, S. Sahebdelfar, M. Asadi, Y.Z. Feng, Effect of SAPO-34's composition on its physico-chemical properties and deactivation in MTO process, Applied Catalysis A: General 364 (2009) 48-56.

[50] W. Song, H. Fu, J.F. Haw, Supramolecular origins of product selectivity for methanol-to-olefin catalysis on HSAPO-34, Journal of the American Chemical Society 123 (2001) 4749-4754.

[51] W. Song, H. Fu, J.F. Haw, Selective synthesis of methylnaphthalenes in HSAPO-34 cages and their function as reaction centers in methanol-to-olefin catalysis, The Journal of Physical Chemistry B 105 (2001) 12839-12843.

[52] B. Arstad, J.B. Nicholas, J.F. Haw, Theoretical study of the methylbenzene side-chain hydrocarbon pool mechanism in methanol to olefin catalysis, Journal of the American Chemical Society 126 (2004) 2991-3001. 


\section{Table captions:}

Table 1. Characterization data of the samples.

Table 3. Textual properties of SAPO-34, Clinoptilolite, SAPO-34/Clinoptilolite.

Table 3. Comparison of performance of prepared nanocomposite catalyst and various reported nanocomposite of SAPO-34 catalysts. 


\section{Figure captions:}

Figure 1. Schematic flow chart for (a) treatment of Clinoptilolite using $\mathrm{HNO}_{3}$, (b) preparation of SAP-34 gel and (c) design of composite catalyst system.

Figure 2. XRD patterns of (a) non-treated Clinoptilolite, (b) $\mathrm{HNO}_{3}$-treated Clinoptilolite, (c) SAPO-34, (d) S/C(50 wt. \%), (e) S/C(70 wt. \%) and (f) S/C(90 wt. \%).

Figure 3. FESEM images of (a) and (b) natural Clinoptilolite, (b) and (c) modified Clinoptilolite.

Figure 4. FESEM images of (a) SAPO-34, (b) H-S/C(50 wt. \%), (c) H-S/C(50 wt. \%) and (d) U-S/C(50 wt. \%), (e) H-S/C(70 wt. \%) and (f) U-S/C(70 wt. \%). (H: Hydrothermal, U: ultrasonic).

Figure 5. TEM images of $\mathrm{S} / \mathrm{C}$ nanocomposite at different magnifications.

Figure 6. Schematic illustration of the nanocomposite catalyst of S/C.

Figure 7. FT-IR spectra of (a) natural Clinoptilolite, (b) modified Clinoptilolite and (c) S/C.

Figure 8. $\mathrm{NH}_{3}-\mathrm{TPD}$ patterns of different samples: natural Clinoptilolite, modified Clinoptilolite, H-SAPO-34. U-SAPO-34 and S/C.

Figure 9. Methanol conversion over the SAPO-34, Clinoptilolite, physical mixture and nanocomposite S/C catalysts. Reaction conditions: Catalyst $=0.5 \mathrm{~g}, 450{ }^{\circ} \mathrm{C}, \mathrm{WHSV}=4.5 \mathrm{~h}^{-1}$, Feed: methanol in water (20 vol. \%).

Figure 10. Product composition with time on stream over the SAPO-34, Clinoptilolite, physical mixture and S/C nanocomposite catalysts. Reaction conditions: Catalyst $=0.5 \mathrm{~g}, 450$ ${ }^{\circ} \mathrm{C}$, WHSV $=4.5 \mathrm{~h}^{-1}$, Feed: methanol in water (20 vol. $\left.\%\right)$. 


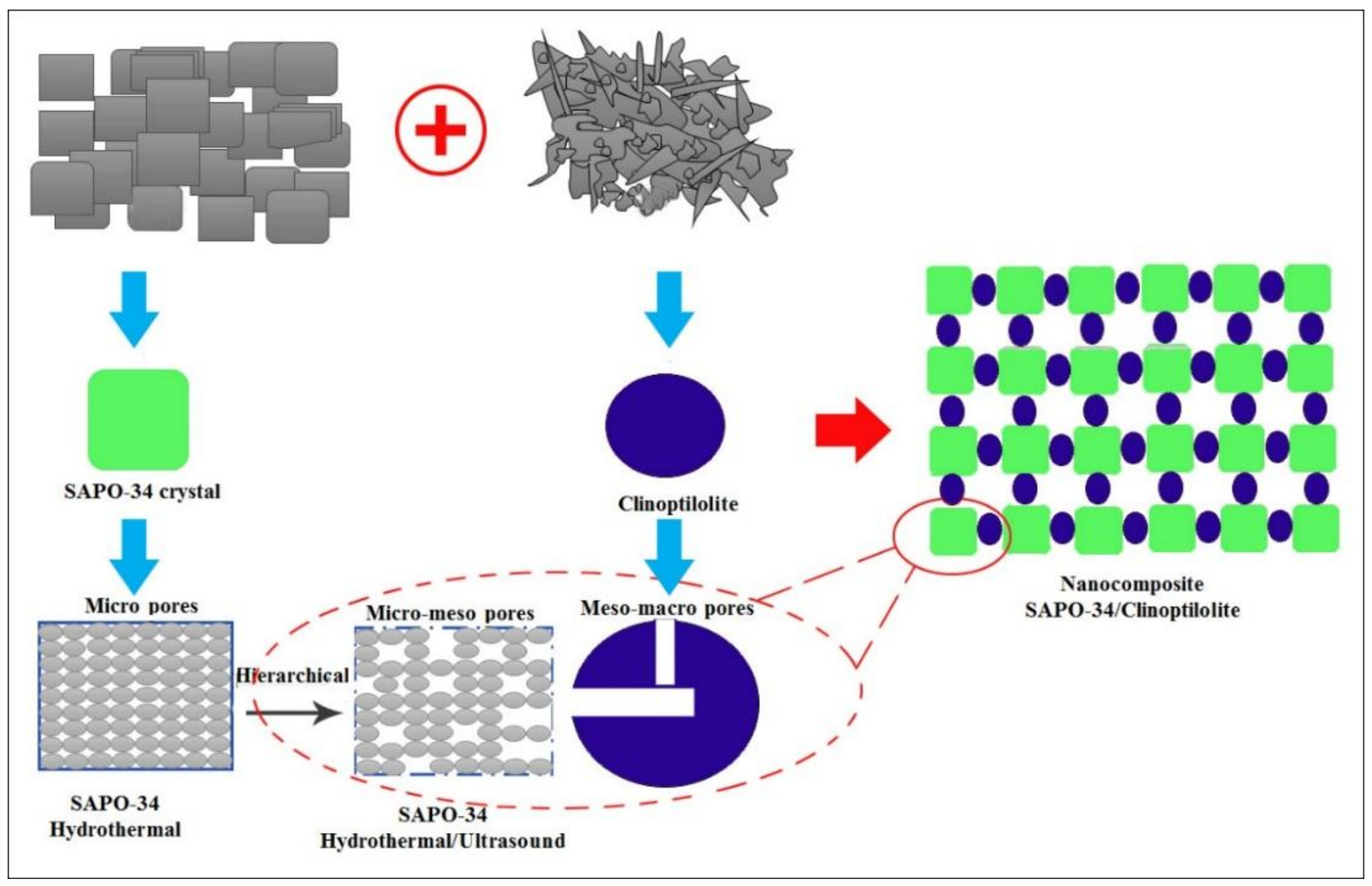

Schematic illustration of the nanocomposite catalyst of SAPO-34/Clinoptilolite 